\title{
Does class participation predict academic achievement? A mixed-method study
}

Uğur Akpur

Yildiz Technical University, Davutpaşa Kampüsü, İstanbul, Türkiye

uakpur@yahoo.com

\section{ARTICLE INFO}

\section{Article history}

Received 24 January 2021

Revised 22 March 2021

Accepted 21 April 2021

\section{Keywords}

class participation

student engagement

student involvement

academic achievement

\section{ABSTRACT}

The present study's aim is to identify whether class participation is a significant predictor of English language achievement among university students and their views concerning class participation and academic achievement. A sequential mixed method design was applied and a total of 2013 university students (813 female 40.3\%; 1200 male, 59.7\%) participated in the quantitative portion of the study. Course Participation Grade (CPG) criteria and English Proficiency Exam (EPE) held at the end of the academic year by the institution were used as data collection tools. The qualitative data were analysed through content analysis of a focus group interview with a group of seven participants. The findings suggested that the relationship between academic achievement and CPG was positive and significant. Correspondingly, the qualitative data revealed similar results with the quantitative data by showing that the class participation has powerful impact on academic achievement.

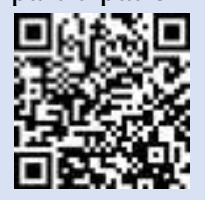

This is an open access article under the CC-BY-SA license.

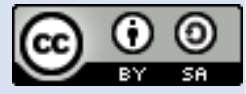

How to Cite: Akpur, Uğur (2021). Does class participation predict academic achievement? A mixed-method study. English Language Teaching Educational Journal, 4(2), 148-160

\section{Introduction}

Establishing effective learning environments in today's increasingly complicated world to promote learning and academic success is one of the most addressed topics in education (Chapman, 2003; Çelik et al., 2018; Hoyert et al., 2019; Kreng, 2013; Kuh et al., 2006, Hopland, \& Nyhus, 2016; Alzubaidi, Aldridge, \& Khine, 2016; Lim \& Fraser, 2018). Although factors affecting learners' success stretch from the individuals' readiness, characteristics, backgrounds to educational policies and practices as well as institutional facilities and many others, students' engagement still stands as a key factor in educational settings (Chapman, 2003; Fredin et al., 2015). To Kuh (2009), as the number of hours that the students spend on a topic increase, they will more likely know and learn better. Accordingly, as they practice and participate in activities more, they will more likely get much more feedback from their teachers and the more in-depth they learn, the more masterfully they can cope with complex and ambiguous situations. In addition, engaging in educational activities also helps individuals develop basic skills to lead a more productive and more satisfactory life even after school life. In other words, engagement helps individuals build a fundamental structure in their minds upon which they can build necessary construction for the concept of lifelong learning.

Regarded as one aspect of student engagement (Frisby, 2015), class participation has also attracted much attention (Baron \& Corbin, 2012; Ko et al., 2016; Skinner et al., 2009, Mundelsee \& Jurkowski, 2021) as one of the essential elements for the successful conduct of a learning activity (Saritepeci, 2012). Generally defined as the verbal interaction among participants in a learning environment (Karima, 2016), class participation connotes any remarks or questions voiced by 
students (Frisby, 2015), students' active involvement in class activities (Ghalley \& Rai, 2019; Lei et al., 2018; Skinner et al., 2009; Bond, Buntins, Bedenlier, S. et al., 2020; Lai, 2021; Sedláček \& Šed'ova, 2020; Sadoughi \& Hejazi, 2021) and endeavours made by students to academic events (Ghasemi et al., 2018). As Chapman (2003) argues, class participation or student engagement traditionally was often described in terms of "time-based indices" such as doing a given task on time or attending classes timely. On the other hand, lately, the term has been depicted as students' enthusiasm or eagerness to attend classes and to take part in class activities. Nowadays, however, another definition of the term has been emphasized. Within this context, participation is identified within three dimensions: affective, cognitive and behavioural (Dotterer et al., 2007; Stefansson et al., 2018).

The affective dimension points out the emotional bond established between students and school, which is called "identification with school" by Voelkl (1997, p. 296). This dimension also applies to positive and negative responses towards the stakeholders of school such as students, teachers, administrators, school board members, parents and school itself as well as touching on the students' commitment to school. Cognitive dimension refers to endeavours and efforts made by students to understand comprehensive and sophisticated ideas as well as the students' use of self-regulatory strategies. The behavioural dimension contains students' "observable actions or performance", such as doing homework, attending classes and school grades (Archambault et al., 2009; Dotterer et al., 2007; Stefansson et al., 2018; Ozdemir, 2017; Wang et al., 2014).

Class participation depicts students' emotions, behaviours and judgements about school life and it is an important variable since it affects academic outcomes such as achievement and high level of school commitment (Dotterer et al., 2007; Engels, Spilt, Denies, \& Verschueren, 2021; Thararuedee \& Wette, 2020). Reviewing the measurements that examine engagement, Ozdemir (2017) suggest that rather than affective and cognitive aspects, behavioural dimension has attracted more attention in terms of investigations. Thus, getting high grades, rate of completing homework or given tasks on time, and time spent on school-related events are generally considered as indicators of participation. In other words, since it could be assessed through monitoring students in the course of learning process, attendance, taking part in activities during classes, tutoring peers and preparedness are observable signs of participation (Syaveny \& Johari, 2017). As a result, examining the link between class participation to other variables and its influence on students' school life have been studied in terms of the mentioned indicators.

Within this context, several studies have revealed that class participation is positively correlated with academic achievement whereas non-participation causes poor academic outcomes. Gürer (2013) found that in social studies lesson, class engagement and academic achievement positively correlated with each other. Likewise, Marks (2000), in her study, pointed that academically successful students are more engaged in class-related activities than those who were not engaged. Sirin and Rogers-Sirin (2004) in their research on African American students also suggested that school engagement was one of the variables that had the strongest relationship with academic performance. The significance of class participation as an indicator of academic achievement was also emphasized in Voelkl's (1997) study. Gunuc's (2014) study, exploring the predictive level of student engagement on academic achievement, revealed the significant relationship between the variables. Similarly, Wang and Eccles (2011) in their study found that school engagement was positively related to academic achievement. Pike, Smart and Ethington's (2012) study in which 20,000 students participated revealed that student participation was significantly correlated with academic success. Ko et al., (2016), in their study where over 18,000 students participated, as well as Konold, Cornell, Jia and Malone's (2018) study including more than 60,000 participants also cited that class participation had significant impact on learning outcomes. In short, the agreed point is that class participation has profound impacts on the academic achievement in positive way.

Similarly, in language learning context, class participation is of crucial importance in terms of positive academic outcomes (Permatasari, 2016; Albertson, 2020). Apart from enabling students in a language class to verbalize their thoughts, emotions and opinions, class participation also promotes their critical thinking and discussion abilities (Karima, 2016). Further, in classes, through participation, students can promote their motivation and productive skills which are fundamental steps in learning a foreign language. Furthermore, as Permatasari (2016) states, when students get involved in activities with their classmates and teachers, their cognitive skill levels raise, the roots of which can be found in socio-cultural theory. Hence, given that participation and taking part in class- 
related activities are indispensable in acquiring a foreign language, the learners become successful in language development at the rate they participate (Hamouda, 2013).

Several studies have explored the link between students' participation and academic achievement, and it seems apparent that the positive and significant relationship between them is indisputable. In a study conducted by Syaveny and Johari (2017), it was found that English learning achievement increased when students' participation was higher. Liu and Jackson (2009) investigated reticence in EFL classes and their study revealed that the more proficient the students, the higher was their participation level. Similarly, Fakeye and Amao's (2013) study suggested that the relationship between participation and academic achievement in Literature in English was positive and significant. Crosthwaite, Bailey and Meeker's (2015) findings from their study also supported the aforementioned results by confirming that there was a positive relationship between class participation and language proficiency levels.

To summarise, although there is a large number of studies that mark the positive impacts of class participation on academic achievement, the relationship between the mentioned variables has not been much matter of interest in terms of university students' participation and English language success specific to Turkish context. To this end, the present study tries to address this gap in an attempt to find an answer to the following research questions:

1. Is class participation a significant predictor of English Language achievement among Turkish university students?

2. What are the Turkish students' views concerning class participation and academic achievement?

\section{Method}

The present study was conducted in sequential mixed methods design in which the collection of qualitative data is followed by the collection of quantitative data (Creswell, 2012). According to Creswell (2017), with the introduction of multiple data collection methods and forms of analysis, more explicit methods are needed to eliminate the complexity of such research. These methods have also been developed to meet the need for the researcher to make a more understandable design. This is a kind of design in which qualitative phase of data collection and analysis are conducted initially and this step is followed by the stage of quantitative data collection and analysis. In the final phase, the findings from the separated data are integrated and interpreted (Berman, 2017). To further analyse the quantitative data, a focus group interview was organized for the part of the qualitative portion of the study. In the present study, it was evaluated that a more precise analysis was required due to the complication in interpreting the quantitative data. In addition, the students' views regarding class participation were significant in that these views could lead to valuable suggestions in terms of planning and formulating participation framework. Thus, it was evaluated that, applying this method best suited the study since it could provide a deeper analysis. In line with the context of sequential mixed method design, in the current study the quantitative part was first conducted and this was followed by the stage of quantitative data collection.

\subsection{Participants}

The study group of the research consisted of university students who attend a preparatory school of a state university in İstanbul, Turkey during 2018-2019 academic year. The study group consisted of 2013 (813 female 40.3\%; 1200 male, 59.7\%) students, chosen randomly from different levels and classes so that they could represent the study population. The age group of the participants were as follows: $85.4 \%(n=1720)$ of the students were between the ages $17-19 ; 12.1 \%(n=243)$ of them were between $20-22$, and $2.5 \%(n=50)$ of them were over 23 years old.

\subsection{Data Collection Tools}

In order to assess students' class participation during the academic year, Course Participation Grade (CPG) criteria, the ultimate main of which is to assess students' efforts in learning was taken into consideration. The English Proficiency Exam (EPE) scores for academic achievement, which is prepared and conducted by the institution, was assessed as another data collection tool for the quantitative part of the study. For the qualitative portion of the study, a focus group interview was conducted with seven voluntary students, four of whom (57\%) were males and three were females $(43 \%)$, that represented the sample. Selected from different classes, the participants were told the 
aim of the interview and the researcher attempted to form a comfortable atmosphere so that the participants could express their opinions and feelings with ease and in a detailed way. The interview took nearly an hour and the participants were encouraged to mention the influence of class participation on academic achievement and the factors that affect class participation. For the reliability of the questions, two English teachers and an expert in curriculum were consulted for their opinions about the questions to be asked during the interview.

\subsection{Course Participation Criteria (CPG)}

The criteria aimed to formulate the items by means of which the students are assessed by teachers are illustrated in Table 1.

Table 1. Course Participation Criteria

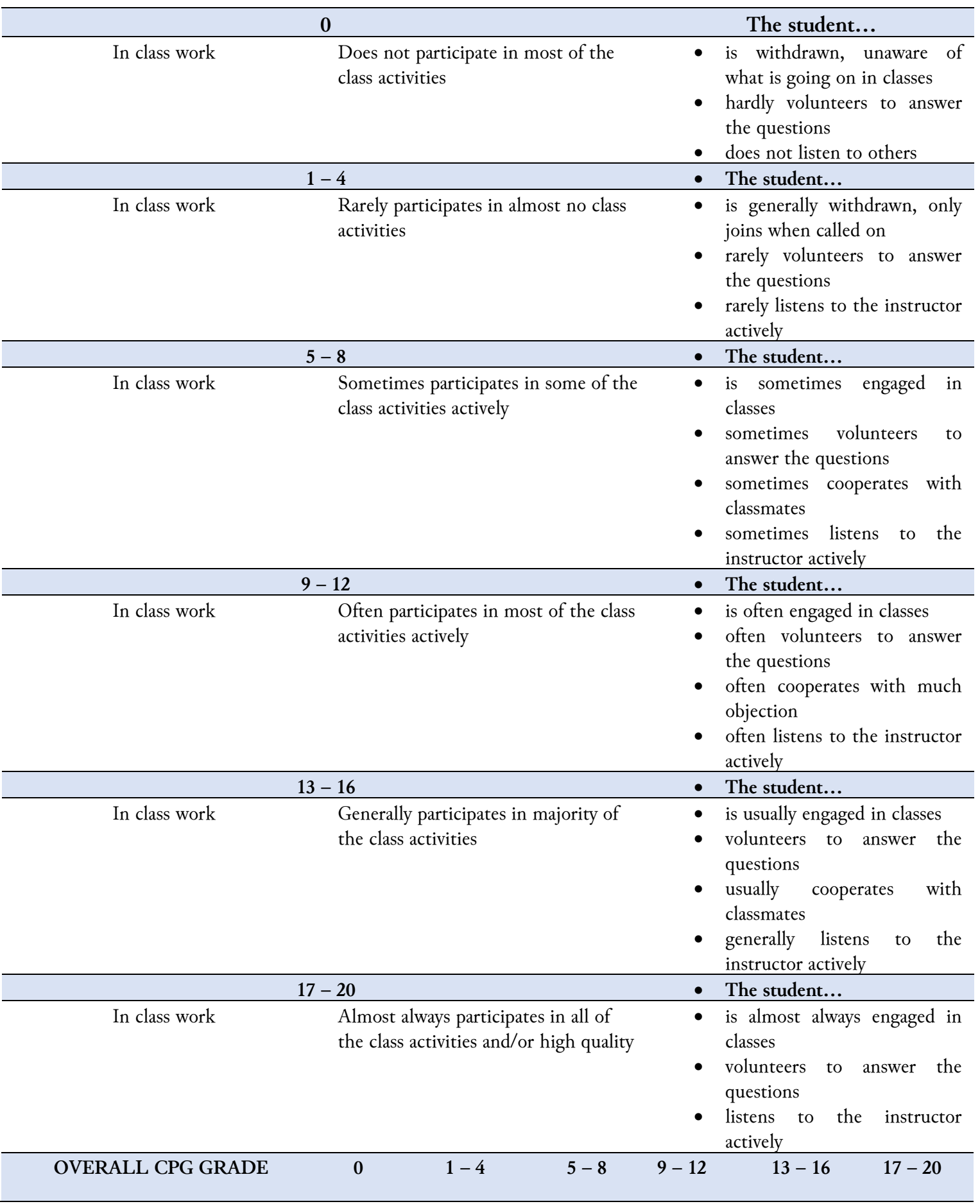


CPG criteria, prepared by the institution, were arranged in a form of rubric ranging from " 0 " to " 20 ". Graded in three-week intervals by all teachers of the class five times in a term, CPG's rubric is scaled in such a way that the ones who do not participate class activities, who are withdrawn and unaware of the goings-on in class, who hardly volunteer to answer the questions raised by the teacher, who use native language excessively and the ones who do not do outside class work are graded "0" point. 1-4 grade scale requires rarely participating in almost no activities, seldom volunteering to answer the question raised, rarely cooperating with classmates, switching to Turkish unnecessarily or not showing any effort to use English and rarely completing or doing poor quality outside class work. Students get 5-8 grades when they sometimes participate in some of the class activities actively, when they are sometimes engaged in activities, sometimes volunteers to answer the questions, sometimes listen to their classmates or teacher and switch to Turkish unnecessarily for the basic words or phrases. These students sometimes complete their assignments and these are average quality. The ones who often participate most of the class activities keenly, are often engaged in classes, often volunteer to answer the questions, often listen to peers or teachers, switch to Turkish when a word or complex structure is not known get 9-12 grades. These students often complete their assignments and these are satisfactorily quality.

Generally participating in majority of activities keenly, often volunteering to answer the questions posed, usually cooperating with peers, and switching to Turkish when the word or phrase is not known and usually completing assignments are graded between 13-16 grades. When students almost always participate in all class activities and when they are regularly volunteers to answer the questions raised by their teachers get 17-20 grades. These students keenly cooperate with their peers, listen to their classmates and teachers, switch to Turkish when they do not know a specific term or a structure and their assignments are almost always complete and high quality. In the present study, CPG grades were analysed in a whole academic year, which connotes that the average of $10 \mathrm{CPG}$ grades were taken into consideration.

\subsection{The English Proficiency Exam (EPE)}

The English Proficiency Exam (EPE), prepared by the institution, is held at the end of every academic year. It is a two-stage exam and designed in line with the Common European Framework of Reference (CEFR). It is aimed to identify whether the students have the proficiency level to follow the courses in their majors. In other words, the purpose of the test is to determine whether the students' proficiency in English is at a level that will enable them to follow courses offered in their respective fields of study and fulfil their requirements with relative ease. Therefore, the English Proficiency Exam (EPE) aims to assess students' ability to comprehend and respond to written and oral academic passages, to understand and follow lectures on semi-academic themes as well as to test their competency levels in producing written texts of various lengths. The exam consists of "Use of English", "Reading", "Listening" and "Writing" sections, which measure reading, listening and writing skills for academic purposes along with grammar and vocabulary. The level of the exam is equivalent to the language proficiency and language skills of a B1+ student according to CEFR. The academic achievement data of the present study were gathered from EPE scores which were held at the end of the academic year in the spring term in 2019. After analysing the items, the difficulty level of the exam was found to be .59 , which shows that the exam was at the "moderately difficult" level. In addition, the reading texts of the EPE were analysed in accordance with Flesch-Kincaid Reading Ease Chart and it was found that they were at "difficult" level whereas the listening part was at "fairly easy" level.

\subsection{Focus Group Interview}

The focus group interview was conducted to interpret the data gained from the quantitative part of the study more thoroughly concerning students' opinions on class participation and academic achievement. Focus group interviews are a method that is conducted within the framework of predetermined guidelines. This method can be defined as a qualitative data collection technique that prioritizes the subjectivity of the interviewees and which should pay attention to the discourse of the participants and the social context (Çokluk et al., 2011). Focus group interviews which aim at unearthing the participants' views about a particular subject matter include questions formed by the interviewer to help the participants express their opinions (Creswell, 2012). The researcher in the present study arranged the interview with seven voluntary students and during the interview the researcher himself explained the aim of the interview comprehensively to make the objectives clear. As for the convenience and the reliability of the interview questions, the literature was reviewed and 
three field-experts were requested for their opinions. To improve and to reach a high level of the coding agreement as much as possible, the researcher and an expert compared the independently formed codes and mutually agreed codes were identified. Richards and Hemphill (2018) reliability formula was applied to provide reliability of analysis and the reliability value was found to be .74 .

\subsection{Data Analysis}

The quantitative data of the study were analysed through SPSS 21.0 software program. To identify the relationship between class participation and academic achievement, correlational analysis was applied. Additionally, simple linear regression analysis was used to explore the predictive power of the independent variable on the dependent variable.

For the quantitative part of the study, correlational survey design was applied. In this type of design, the types of relationships between two or more variables are investigated. In other words, it identifies whether the variables are related and in what way they are related (Karasar, 2003). Additionally, simple linear regression analysis was used to explore the predictive power of the independent variable on the dependent variable. In this kind of research design, it is aimed to determine the relationship level between two variables, one of which is determined as the independent variable and the other as the dependent (Büyüköztürk, 2011).

As for the qualitative part of the study, content analysis was applied for the associated codes, categories, and themes. The content analysis focuses on what is uttered, written or recorded. With the help of systematic organization for the process of determining coding, categories and themes, content analysis is considered as a research method for the clarification and comment of the content (Hsieh \& Shannon, 2005). Within this context, the students' answers during the interview shed light on identifying the codes, categories and themes. After the transcription of the recorded interview, the transcript was first coded and the associated codes were analysed to determine categories and themes. The same steps were taken by another expert to ensure the reliability. The similarity of the codes, categories and themes were controlled through Richards and Hemphill (2018) reliability formula and the reliability of the analysis was found to be over $70 \%$.

\section{Findings and Discussion}

\subsection{Findings}

In the present study, the aim is to identify whether class participation is a significant predictor of English language achievement among university students and to explore students' views in terms of class participation and academic achievement. To this end, the quantitative data obtained from the participants have been analysed and the range, minimum, maximum, medium along with standard error and standard deviation values have been calculated. The findings are illustrated in Table 2.

Table 2. The Range, Minimum, Maximum, Medium, Standard Error, Standard Deviation Values of the Variables

\begin{tabular}{cccccccc}
\hline & N & Range & Min. & Max. & X-Value & SE & SD \\
\hline Academic Achievement & 2013 & 83.75 & 14.00 & 97.75 & 61.05 & .31 & 13.73 \\
CPG & 2013 & 75.00 & 25.00 & 100.00 & 91.33 & .23 & 10.00 \\
\hline
\end{tabular}

As can be observed in Table 2, and the range, minimum, maximum, medium along with standard error and standard deviation values of academic achievement are $83.75 ; 14.00 ; 97.75 ; 61.05 ; .31$ and 13.73 respectively. The figures of CPG for range, minimum, maximum, medium, standard error, standard deviation values are found to be $75.00 ; 25.00 ; 100.00 ; 91.33 ; .23$ and 10.00 .

To identify the regression figures, Pearson Correlation analysis has been applied to determine whether there is a relationship between the variables. The figures of the findings are illustrated in Table 3. 
Table 3. The Values of the Correlation Analysis between the Variables

\begin{tabular}{ccc}
\hline & Academic Achievement & CPG \\
\hline Academic Achievement & 1 & $.28^{* *}$ \\
CPG & $.28^{* *}$ & 1 \\
\hline
\end{tabular}

Table 3 demonstrates the correlation values between CPG and academic achievement. It can be observed that the relationship between academic achievement and CPG is positive and significant at the level of $p<0.01$. In Table 4 , the findings after the regression analysis between academic achievement and CPG has been illustrated.

Table 4. The Results of Regression Analysis of Prediction Degree of Students' Class Participation on Academic Achievement

\begin{tabular}{|c|c|c|c|c|c|}
\hline & B & SE & $\beta$ & $\mathrm{t}$ & p \\
\hline Stable & 33.12 & 3.18 & & 8.13 & $.00^{* *}$ \\
\hline CPG & .43 & .04 & .25 & 6.15 & $.00^{* *}$ \\
\hline
\end{tabular}

In order to identify how much of the total variance in academic achievement is explained by the independent variable (CPG), the regression analysis has been applied. As it is illustrated in Table 4, $38 \%\left(\mathrm{R}^{2}=.38\right)$ of the variance in academic achievement is explained by $\mathrm{CPG}$ grades. The prediction degree has been found to be $\mathrm{F}=84.66$, which is significant at the level of $\mathrm{p}<0.01$. As for the predictive level of the independent variable $\mathrm{CPG}$, it is observed that the power of $\mathrm{CPG}(\mathrm{t}=6.15$, $\mathrm{p}<0.01$ ) to predict academic achievement is meaningful. In other words, it can be concluded that independent variable, CPG is a significant predictor of the dependent variable, academic achievement.

\subsection{The Qualitative Data}

The students' views on class participation and academic achievement along with the factors that affect students' participation in the class-related activities were sought for an answer through the focus group interview. The students' views on class participation and academic achievement along with the factors that affect students' participation in the class.

After transcription of the recorded interview, the transcript was first coded and the associated codes were analysed to determine categories and themes. The content analysis demonstrated that two themes emerged in terms of the class participation and academic achievement along with the factors that affect students' participation in the class.

As can be seen in Table 5, the participants' views on class participation and academic achievement focused on two themes: internal and external factors. Nearly all of the students made it clear that class participation activities would in the end affect their performance and naturally their academic achievement: "It helps the teacher give me a high grade in CPG and I usually remember easily the subjects I talked about" (S4, Female, 18); I know I have to participate, because it increases my performance" (S3, Female, 18). In another word, common views were gathered around the idea that anything to do with participation both enhanced the participants' motivation towards the class and, naturally, helped to improve their performance: "When I participate, this makes me feel more confident" (S2, Male, 19). Further, the from the participants' views, in the theme of internal factors, two categories, respectively, gain and interest were formed. In the gain category, eagerness to learn and positive impression came to the fore. In the interest category, confidence, curiosity and having knowledge were marked. 
Table 5. Class Participation and Academic Achievement as well as the Factors Affecting Students' Participation in the Class

\begin{tabular}{clll}
\hline Theme & Category & Sample Codes & \multicolumn{1}{c}{ Quotation } \\
\hline Internal & Gain & Eagerness to learn & "When I attempt to answer a question, firstly I always \\
Factors & & $\begin{array}{l}\text { Positive } \\
\text { impression }\end{array}$ & $\begin{array}{l}\text { think that this is a good opportunity to show myself. It } \\
\text { helps the teacher give me a high grade in CPG and I } \\
\end{array}$ \\
& & usually remember easily the subjects I talked about." \\
& &
\end{tabular}

Interest $\quad$ Confidence When the subject interests me, it is always easier for Curiosity me to say something, because in these situations, I Having knowledge usually have something to say and participate the class like something about sports. When I participate, this makes me feel more confident." (S2, Male, 19)

\begin{tabular}{|c|c|c|c|}
\hline $\begin{array}{l}\text { External } \\
\text { Factors }\end{array}$ & Respect & $\begin{array}{l}\text { Peer pressure } \\
\text { Lack of confidence } \\
\text { Criticism }\end{array}$ & $\begin{array}{l}\text { "... Sometimes, when I try to answer a question that } \\
\text { the teacher asks, I am often afraid of making mistakes, } \\
\text { because when I say something wrong, my friends } \\
\text { behave like children. But I know I have to do it, } \\
\text { because it increases my performance." (S3, Female, 18) }\end{array}$ \\
\hline
\end{tabular}

$\begin{array}{lll}\begin{array}{l}\text { Classroom } \\ \text { Climate }\end{array} & \begin{array}{l}\text { Crowd } \\ \text { Silence }\end{array} & \begin{array}{l}\text { "If the class is too crowded and I am not sure about the } \\ \text { answer, I never participate or attempt to participate. } \\ \text { This makes me tense and I prefer only to listen to the } \\ \text { teacher." (S1, Male, 19) }\end{array} \\ \text { Teacher } & \begin{array}{l}\text { Positive Feedback } \\ \text { Mind } \\ \text { Support }\end{array} & \begin{array}{l}\text { "When I say something and if the teacher pays } \\ \text { attention to my opinions, I feel relaxed and I begin to } \\ \text { think about giving answers positively." (S5, Female, 19) }\end{array}\end{array}$

As for the theme external factors, respect from the teacher and the peers, classroom climate and the attitude of the teacher were highlighted by the participants. In the respect category the codes, peer pressure, lack of confidence and criticism attracted attention. The codes crowd and silence were found to be related to classroom climate category. The positive feedback from the teacher as well as the peers and support from them were the codes of the teacher category. In other words, during the interview, they also highlighted some other points related to class participation. What they emphasized was that the participation activities were affected by some factors such as interests, gains, and respect from the teacher and peers as well as classroom climate. Another point that the students particularly emphasized was that the teacher's attitudes towards them generally determine their desire for participation.

\subsection{Discussion}

What the present study has sought is to identify the relationship between class participation and academic achievement as well as the predictive level of the participation of on academic achievement. In an attempt to describe the kind of relationship, correlation and regression analysis were conducted and the findings of the present study illustrated that the relationship between class participation and academic achievement was positive and significant at the level of $p<0.01$ and that much of the variance in academic achievement could be explained by the notion of class performance. An important insight that CPG grades explain 38\% of academic achievement has been obtained from the study. It is believed that by marking the significant and positive relationship between class participation and academic achievement, the present study will shed light on certain applications, particularly in terms of the importance of interactive classroom atmosphere. The findings of the study support the views of Kuh et al. (2006), stating that class participation has positive and profound impacts on achievement in that participation and engagement have been assessed as the central theme since it connects learners' behaviours and institutions' objectives and conditions. Moreover, the positive effect of class participation, which is expressed as one of the 
primary elements for the learning process (Saritepeci, 2012; Syaveny \& Johari, 2017) has also been highlighted by Permatasari (2016) who suggests that class participation is thought to enhance students' cognitive abilities and naturally their academic performance. The findings of the current study highlight the mentioned assumptions and are in line with several studies conducted in different settings. Although the level of the aforementioned positive correlation varies from one study to another, the link between the variables has been well stated and determined. Studies conducted by Syaveny and Johari (2017), Gürer (2013), Marks (2000), Liu and Jackson (2009), and Fakeye (2013) have pointed that the more students participate, the higher grades they have in terms of academic achievement. Further, Mijatovic and Jednak (2011) in their study have suggested that the experience of class participation is a strong predictor of academic achievement. In Kelsen and Liyang's (2012) study, it has been emphasized that participation in English-taught programs is one of most significant indicators of academic achievement. Furthermore, Ko et al., (2016), analysing over 18.000 students' replies, argue that class participation is one of the important variables that has strong influence on learning outcomes. On the other hand, in the study of Niia et al. (2015), it has been concluded that parents, teachers and students attribute different meanings to the notion of participation and its relationship to the academic achievement. For the students, in the study, class participation is a means of socializing while the teachers view it as an activity which is closely connected with academic achievement.

The qualitative data gained through the present study have also yielded to important findings. First of all, the majority of students have underlined the fact that participating in class activities or learning-related activities affect their performance in the learning process positively. Said another way, the dominant views during the interview have been grounded on the idea that anything related to participation promotes motivation which, in the end, have reflections on the academic achievement in a positive way. From the qualitative portion of the study it has also been highlighted that there are some factors affecting class participation such as interests, gains, and respect from the teacher and peers as well as classroom climate. From the content analysis, it is possible to draw the conclusion that these factors are of almost equal importance with effect of participation over performance. It is observed that in some other studies too, the factors that have influence over performance have been stressed. A study conducted by Susak (2016) which examines the factors that affect class participation has underlined that logistics, student traits, classroom climate, and the teacher's effect influence participation activities. Similarly, Ghalley and Rai (2019) have concluded that teachers, peers, the size of the classroom, preparation for the class and proficiency in language are the main factors that influence class participation. In another study conducted by Precourt and Gainor (2019), the featured factors in class participation have been sorted as class schedule, class duration and semester. In the same study, it is also concluded that the students who take part in class activities more in classroom discussions perform $25 \%$ better on exams than the ones who display lower participation activities. Further, Aziz et al. (2018) in their study have found that self-esteem and motivation as internal factors; teachers, parents, peers and curriculum as the external factors influence participation in classrooms. In the light of empirical findings and theoretical frames, it can be concluded that the factors affecting class participation vary from one context to another, thus requiring special consideration peculiar to a specific context.

\section{Conclusion}

As an overall conclusion, it can be concluded that class participation is a significant variable in terms of promoting motivation, self-confidence and thus academic achievement. It is also particularly helpful to identify and set forth the factors that affect achievement. From the current study, it has been found that class participation is an important variable that has a deep influence over the concept of achievement. The present study leads to some educational implications, as well. In the first place, what is to be highlighted regarding teachers' role in classes is to create convenient atmospheres to promote participation as much as possible where students can feel themselves free and comfortable in joining. In this respect, it gains prominence that the students should be encouraged to engage in class activities by teachers. Secondly, teachers and policy makers have to make point of providing positive attitudes to students' efforts towards participation as it has been emphasized as an important factor that leads to the frequency of participation. It is a known fact that the fear of being ridiculed by their peers, lack of self-confidence and lack of courage could prevent students from participating in the classroom activities. In the present study, the participants of the 
focus group mentioned similar points, which could hinder their eagerness to participate. At this point, getting to know the names of students, making them study in pairs, listening and responding them appropriately, giving importance to their ideas, creating a class atmosphere in which they can teach each other and using technological tools that help them express their ideas freely could contribute to create a non-threatening classroom climate in which their ideas and feelings are valued.

It is to be made point of a couple of certain limitations of the present study. In the first place, the data that were analysed gained from the university students attending preparatory classes. Studying with the students from other nationalities, departments, sections and age groups may yield to different findings. In addition, although it might cause certain difficulties in the process of contentanalysis, the number of the focus-group members could be increased more to get more accurate results.

\section{REFERENCES:}

Albertson, B. P. (2020). Promoting Japanese university students' participation in English classroom discussions: Towards a culturally-informed bottom-up approach. Journal of Pan-Pacific Association of Applied Linguistics, 24(1), 45-66.

Alzubaidi, E., Aldridge, J. M., \& Khine, M. S. (2016). Learning English as a second language at the university level in Jordan: Motivation, self-regulation and learning environment perceptions. Learning Environments Research, 19(1), 133-152.

Archambault, I., Janosz, M., Fallu, J., \& Pagani, L. S. (2009). Student engagement and its relationship with early high school dropout. Journal of Adolescence, 32(3), $651-670$. https://doi.org/10.1016/j.adolescence.2008.06.007

Aziz, F., Quraishi, U., \& Kazi, A. S. (2018). Factors behind classroom participation of secondary school students (A gender based analysis). Universal Journal of Educational Research, 6(2), 211-217.

Baron, P., \& Corbin, L. (2012). Student engagement: Rhetoric and reality. Higher Education Research \& Development, 31(6), 759 - 772.

Berman, E. A. (2017). An exploratory sequential mixed methods approach to understanding researchers' data management practices at UVM: Integrated findings to develop research data services. Journal of eScience Librarianship, 6(1): e1104. https://doi.org/10.7191/jeslib.2017.1104

Bond, M., Buntins, K., Bedenlier, S. et al. (2020). Mapping research in student engagement and educational technology in higher education: a systematic evidence map. International Journal of Educational Technology in Higher Education 17, 2 https://doi.org/10.1186/s41239-019-0176-8

Büyüköztürk, Ş. (2011). Sosyal bilimler için veri analizi el kitabı: İstatistik, araştırma deseni, $\quad$ SPSS uygulamaları ve yorum. Ankara: Pegem Yayınc1lık

Çelik, S.,Toraman, S. Ö., \& Çelik, K. (2018). Öğrenci başarısının derse katılım ve öğretmen yakınlığıyla ilişkisi. Kastamonu Eğitim Dergisi, $26(1), \quad 209 \quad$ - 217. https://doi.org/10.24106/kefdergi.378129

Chapman, E. (2003). Alternative approaches to assessing student engagement rates. Practical Assessment, Research \& Evaluation, 8(13), 1 - 7.

Creswell, J. W. (2012). Educational research: Planning, conducting, and evaluating quantitative and qualitative research. Boston: Pearson Education.

Creswell, J. W., \& Creswell, J. D. (2017). Research design: Qualitative, quantitative, and mixed methods approaches. Melbourne: Sage publications.

Çokluk, Ö., Yılmaz, K., \& Oğuz, E. (2011). Nitel bir görüşme yöntemi: Odak grup görüşmesi. Kuramsal Ĕgitimbilim, 4(1), 95 - 107.

Crosthwaite, P. R., Bailey, D. R., \& Meeker, A. (2015). Assessing in-class participation for EFL: considerations of effectiveness and fairness for different learning styles. Language Testing in Asia, 5(9), 1 - 19. https://doi.org/10.1186/s40468-015-0017-1 
Dotterer, A. M., McHale, S. M., \& Crouter, A. C. (2007). Implications of out-of school activities for school engagement in African American adolescents. J Youth Adolescence, 36, 391 - 401. https://doi.org/10.1007/s10964-006-9161-3

Engels, M. C., Spilt, J., Denies, K., \& Verschueren, K. (2021). The role of affective teacher-student relationships in adolescents' school engagement and achievement trajectories. Learning and Instruction, 75, https://doi.org/10.1016/j.learninstruc.2021.101485

Fakeye, D. O., \& Amao, T. A. (2013). Classroom participation and study habit as predictors of achievement in literature-in-English. Cross-Cultural Communication, $9(3), \quad 18 \quad-\quad 25$. https://doi.org/10.3968/j.ccc.1923670020130903.2741

Fredin, A., Fuchsteiner, P., \& Portz, K. (2015). Working toward more engaged and successful accounting students: A balanced scorecard approach American Journal of Business Education, 8(1), 49 - 62.

Frisby, B. N. (2015). Effective instructional practice: Facilitating student participation. Retrieved from: https://www.natcom.org/sites/files/pages/EIP_Student_Participation

Ghalley, L. R., \& Rai, B. M. (2019). Factors influencing classroom participation: A case study of Bhutanese higher secondary student. Asian Journal of Education and Social Studies, 4(3), 1 - 14, https://doi.org/10.9734/AJESS/2019/v4i330118

Ghasemi, M. R., Moonaghi, H. K., \& Heydari, A. (2018). Student-related factors affecting engagement: A qualitative study exploring the experiences of Iranian undergraduate students. Electronic Physician, 10(7), 7078 - 7085. http://dx.doi.org/10.19082/7078

Gunuc, S. (2014). The relationships between student engagement and their academic achievement. International Journal on New Trends in Education and Their Implications, 5(4), 216 - 231.

Gürer, M. D. (2013). Utilization of learning objects in social studies lesson: Achievement, attitude and [Unpublished $\quad$ Master https://etd.lib.metu.edu.tr/upload/12615348/index.pdf

Hamouda, A. (2013). An exploration of causes of Saudi students' reluctance to participate in the English Language classroom. International Journal of English Language Education, 1(1), 17 - 34. https://doi.org/10.5296/ijele.v1i1.2652

Hopland, A. O., \& Nyhus, O. H. (2016). Learning environment and student effort. International Journal of Educational Management, 30(2), pp.271-286.

Hoyert, M. S., Ballard, K., \& O’Dell, C. D. (2019). Increasing student success through a cocktail of cognitive interventions. Journal of the Scholarship of Teaching and Learning, 19(1), 128 - 134. https://doi.org/10.14434/josotl.v19i1.26778

Hsieh, H.-F., \& Shannon, S.E. (2005). Three approaches to qualitative content analysis. Qualitative Health Research, 15(9), 1277 - 1288.

Karasar, N. (2003). Bilimsel Araştırma Yöntemi. Ankara: Nobel Yayınları.

Karima, H. (2016). An investigation of the difficulties that prevent EFL learners from participation. [Unpublished Master Thesis]. https://e-biblio.univ-mosta.dz

Kelsen, B. A., \& Liyang, H. (2012). Indicators of achievement in EFL classes at a Taiwanese University. Education Research International, 2012, 1 - 8. https://doi.org/10.1155/2012/635964

Ko, J. W., Park, S., Yu, H. S., Kim, S-J., \& Kim, D. M. (2016). The structural relationship between student engagement and learning outcomes in Korea. The Asia-Pacific Education Researcher, 25(1):147 - 157. https://doi.org/10.1007/s40299-015-0245-2

Konold, T., Cornell, D., Jia, Y., \& Malone, M. (2018). School climate, student engagement, and academic achievement: A latent variable, multilevel multi-informant examination. American Educational Research Association, 4(4), 1 - 17. https://doi.org/10.1177/2332858418815661

Kreng, H. (2013). Factors influencing college students' academic achievement in Cambodia: A case study. AJTLHE, 5(2), 34 - 49. 
Kuh, G. (2009). The national survey of student engagement: Conceptual and empirical foundations. New Directions for Institutional Research, 141, 5 - 20.

Kuh, G. D., Kinzie, J., Buckley, J. A., Bridges, B. K., \& Hayek, J. C. (2006). What matters to student success: A review of the literature. Final report for the National Postsecondary Education Cooperative and National Center for Education Statistics. Bloomington, IN: Indiana University Center for Postsecondary Research. Retrieved from: http://nces.ed.gov/npec/papers.asp

Lai, H. M. (2021). Understanding what determines university students' behavioral engagement in a groupbased flipped learning context. Computers \& Education, https://doi.org/10.1016/j.compedu.2021.104290

Lei, H., Cui, Y., \& Zhou, W. (2018). Relationships between students' engagement and academic achievement: A meta-analysis. Social Behaviour and Personality, 46(3), 517 - 528. https://doi.org/10.2224/sbp.7054

Lim, CT.D., Fraser, B.J. (2018). Learning environments research in English classrooms. Learning Environments Research 21, 433-449, https://doi.org/10.1007/s10984-018-9260-6

Liu, M., \& Jackson, J. (2009). Reticence in Chinese EFL students at varied proficiency levels. TESL Canada Journal, 26(2), 65 - 81.

Marks, H. M. (2000). Student engagement in instructional activity: Patterns in the elementary, middle, and high school years. American Educational Research Journal, 37(1), 153 - 184

Mijatovic, I., \& Jednak, S. (2011). Attitudes toward active participation as predictors of student achievement - Exploratory research from Serbia. The New Educational Review, 24(2), 258 - 270.

Mundelsee, L., \& Jurkowski, S. (2021). Think and pair before share: Effects of collaboration on students' inclass participation. Learning and Individual Differences, 88, 102015. https://doi.org/10.1016/j.lindif.2021.102015

Niia, A., Almqvist, L., Brunnberg, E., \& Granlund, M. (2014). Student participation and parental involvement in relation to academic achievement. Scandinavian Journal of Educational Research 59(3), 1 - 19. https://doi.org/10.1080/00313831.2014.904421

Ozdemir, M. (2017). Examining the relations among social justice leadership, attitudes towards school and school engagement. https://doi.org/10.15390/EB.2017.6281

Permatasari, R. (2016). What do the studies say about the factors obstructing EFL/ESL students' participation? Paper presented at the $5^{\text {th }}$ English Language Teaching, Literature, and Translation International Conference 2016. Faculty of Languages \& Arts State University of Semarang

Pike, G. R., Smart, J. C., \& Ethington, C. A. (2012). The mediating effects of student engagement on the relationships between academic disciplines and learning outcomes: An extension of Holland's Theory. Research in Higher Education, 53(5), 550 - 575. https://doi.org/10.1007/s11162-011-9239-y

Precourt, E., \& Gainor, M. (2019). Factors affecting classroom participation and how participation leads to a better learning. Accounting Education, $28(1), \quad 100 \quad-\quad 118$. https://doi.org/10.1080/09639284.2018.1505530

Richards, K. A. R., \& Hemphill, M. A. (2018). A practical guide to collaborative qualitative data analysis. Journal of Teaching in Physical Education, 37(2), 225-231.

Sadoughi, M., \& Hejazi, S. Y. (2021). Teacher support and academic engagement among EFL learners: The role of positive academic emotions. Studies in Educational Evaluation, 70, https://doi.org/10.1016/j.stueduc.2021.101060

Saritepeci, M. (2012). The effect of blended learning environment on students' engagement, academic achievement, attitude and motivation to the course of social studies in seventh grade in primary education. [Unpublished Master's Thesis]. https://kefad.ahievran.edu.tr/InstitutionArchiveFiles/f44778c7.pdf 
Sedláček, M., \& Šed'ova, K. (2020). Are student engagement and peer relationships connected to student participation in classroom talk?.Learning, Culture and Social Interaction, 26, https://doi.org/10.1016/j.lcsi.2020.100411

Sirin, S. R., \& Rogers-Sirin, L. (2004). Exploring school engagement of middle-class African American adolescents. Youth \& Society, 35(3), 323 - 340. https://doi.org/10.1177/0044118X03255006

Skinner, E. A., Kindermann, T. A., \& Furrer, C. J. (2009). A motivational perspective on engagement and disaffection. Conceptualization and assessment of children's behavioural and emotional participation in academic activities in the classroom. Educational and Psychological Measurement, 69(3), 493 - 525. https://doi.org/10.1177/0013164408323233

Stefansson, K. K., Gestsdottir, S., Birgisdottir, F., \& Lerner, R. M. (2018). School engagement and intentional self-regulation: A reciprocal relation in adolescence. Journal of Adolescence, 64, 23-33.

Susak, M. (2016). Factors that affect classroom participation. [Unpublished Master's Thesis]. https://scholarworks.rit.edu/theses

Syaveny, N., \& Johari, I. (2017). The correlation between class participation and students' English learning achievement at SMA Negeri 12 Padang KEC. Naggalo West Sumatera. International Seminar on Language, Education, and Culture Proceeding, 208 - 211.

Thararuedee, P., \& Wette, R. (2020). Attending to learners' affective needs: Teachers' knowledge and practices. System, 95, https://doi.org/10.1016/j.system.2020.102375

Voelkl, K. E. (1997). Identification with school. American Journal of Education, 105, 294 -

318.

Wang, M. T., \& Eccles, J. S. (2011). Adolescent behavioural, emotional, and cognitive engagement trajectories in school and their differential relations to educational success. Journal of Research on Adolescence, 22(1), 31 - 39. https://doi.org/10.1111/j.1532-7795.2011.00753.x

Wang, Z., Bergin, C., \& Bergin, D. A. (2014). Measuring engagement in fourth to twelfth grade classrooms: The classroom engagement inventory. School Psychology Quarterly, 29(4), 517 - 535. https://doi.org/10.1037/spq0000050 